\title{
織維強化による高強度ゲルの開発*
}

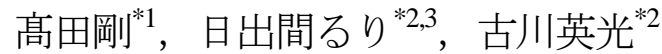

\section{Fiber Reinforced Gels with High Strength}

\author{
Go TAKADA, Ruri HIDEMA and Hidemitsu FURUKAWA ${ }^{* 2}$
}

${ }^{* 2}$ Soft \& Wet matter Engineering Laboratory (SWEL),

Department of Mechanical Systems Engineering, Graduate School of Science and Engineering,

Yamagata University, Jonan 4-3-16, Yonezawa, Yamagata, 992-8510, Japan

After 2001, several methods have been devised to improve the mechanical strength of gels extraordinarily. It was a trigger to use gels as a new industrial materials, since gels had been considered difficult for industrial materials because of their weakness. The purpose of this study is to create novel composite materials, which realizes the further high strength of gels by adding fiber to the gels. We evaluated the mechanical properties of the gels, containing a very small amount of the fiber, in order to quantify how the fiber works for enhancement of the gels. It is found that to improve the adhesion between fiber and the gel matrix is important for increasing the mechanical strength of the newly proposed gels. Since there are many kinds of gels and fibers, it becomes possible to achieve a dramatic enhancement of the strength if we find an appropriate combination for rigid adhesion.

Key Words : Composite Materials, Acrylic Fiber, Tensile Test, Young's Modulus, Maximum Strength

\section{1. 緒言}

ゲルは溶媒を含んだ高分子の三次元網目構造であり，高い含水率のために柔軟で，低摩擦係数や物質透過性，生 体適合性を併せもつ。これは金属，セラミックス，プラスチックなどの堅い材料にはない性質である。しかし，一 般的なゲルの圧縮破断応力は $0.1 〜 0.4 \mathrm{MPa}$ と他の材料に比べて低く, 工業材料としての応用は難しいとされてきた. 2001 年以降, ゲルの画期的な強化方法 ${ }^{(1-8)}$ が次々と考案された. 特に世界最高強度を誇るダブルネットワークゲル (3) の圧縮破断応力は最大で $30 \mathrm{MPa}$ にまで達し, 飛躍的な強化がなされた. これにより例えば人工関節軟骨などへの生 体材料としての応用可能性が示された. また 2011 年には, ゲルにおける新規な網目構造である相互架橋網目構造 $(9,10)$ が開発された. 相互架橋網目構造は複数の異なる高分子によって構成された網目構造であり、相互架橋網目構造に よってゲルの延性の向上が可能となった. これらのゲルの機械的強化方法の進歩により，ゲルは新たな工業材料と して注目されている.これまでにゲルの強化法として有効性が確認されたのは，どれも分子構造制御による化学的 方法である. 一方，攵ルに他の材料を添加して強化する複合化についての研究は少なく，我々の知る限りその有効 性はまだ示されていない，我々はゲルの複合化の手法が確立されれば，簡便な強化が可能になり，ゲルの工業材料 としての多用性が向上すると考えた.

本研究の目的は，ゲルに䋊維を加えることで高強度の繊維強化ゲル材料を作り出すことである。この方法は複合 ゲルという新しい発想の材料の創成に知見を与える．試作したゲルの力学物性を解析し，繊維とゲルの関係性を考 察する. ゲルや繊維には数多くの種類があり, それらの組み合わせ次第では力学物性の飛踓的な向上が期待できる.

\section{2. 実 験}

\section{$2 \cdot 1$ 材料}

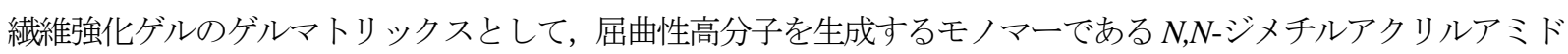
( $N, N$-Dimethylacrylamide, DMAAm) を使用した。架橋剂に $N, N$-メチレンビスアクリルアミド

\footnotetext{
*原稿受付 2012 年 3 月 27 日

${ }^{* 1}$ 山形大学大学院 理工学研究科 機械システム工学専攻（テ992-8510 山形県米沢市城南 4-3-16)

*2 正員, 山形大学大学院 理工学研究科 機械システム工学専攻（†992-8510 山形県米沢市城南 4-3-16)

*3 正員, 神戸大学 自然科学系先端融合研究環（广657-8501 兵庫県神戸市灘区六甲台町 1-1）

E-mail: furukawa@yz.yamagata-u.ac.jp
} 
（N,N’-methylenbisacrylamide, MBAA），光開始剤に $\alpha$-ケトグルタル酸（ $\alpha$-ketoglutaric acid, $\alpha$-keto）を用いた. 波長が 365nm のUV ライトを照射しゲル化を開始させた。ここでは，このゲルをPDMAAm ゲルと呼ぶ. ゲルに添加した 剛直性の䋊維である，アクリル短繊維（三菱レイヨン製）を図 1 に示す。このアクリル短繊維は長さ $3 \mathrm{~mm}$ ，線密度 0.1dtex，1 本あたりの質量は $3.0 \times 10^{-7} \mathrm{~g}$ であった，網目のサイズが $\mathrm{nm}$ スケールである PDMAAm ゲルに，高い岡性 と 勒性をもち太さが $\mu \mathrm{m}$ スケールであるアクリル短䋊維を添加することで，ゲル内でアクリル短繊維が骨組みの 役割を果たし，ゲルの強度が高まることを期待した。 DMAAm とアクリル短繊維の親和性を高めるために MMA

(methyl methacrylate) を使用した. 図 2 に示すように MMAがアクリル短䋊維内部にまで化学結合的で浸透するこ とにより，DMAAm とアクリル短繊維の接着性が向上することを期待した.

\section{$2 \cdot 2$ 纎維強化ゲルの合成}

屈曲性高分子を生成するモノマーである DMAAm を純水に添加し, 溶解するまで撹拌した. 溶解後, 架橋剤であ る MBAA と光開始剤である $\alpha$-keto を加え攪拌した (薬品はすべて和光純薬工業製であり,未精製で用いた). 次に, アクリル短繊維に MMA を添加し，アクリル短䋊維内に MMA が浸透するまで 30 分間静置した. その後, DMAAm 溶液に，MMA を浸透させたアクリル短䋊維を加えてプレゲル溶液を調製した．プレゲル溶液の試薬の比率を表 1 に示す.この表の意味は，まずDMAAm を $2 \mathrm{~mol} / \mathrm{l}$ と決め，この $2 \mathrm{~mol}$ に対して MMA と $\alpha$-keto をそれぞれ $2 \%$ と $0.1 \%$ 添加したということである. 調製したプレゲル溶液を，1mmのシリコーンスペーサーを挟んだ 2 枚のガラス板の間 に流し込んで鋳型とし，紫外光を約 9 時間照射してゲル化させた. その後，ゲルが十分に水を吸い，平衡状態に達 するように，大量の純水中に 24 時間以上浸し膨閏させた. 合成した䋊維強化ゲル（MMA30mol\%添加）を図 3 に示 す.アクリル短䋊維は DMAAm に対して $0 ， 0.1 ， 0.2 ， 0.3 ， 0.4 ， 0.5 w t \% の$ 割合で加えた. また，MMAはモノマー である DMAAmに対して 0，10，20，25，30mol\%の割合で加えた.

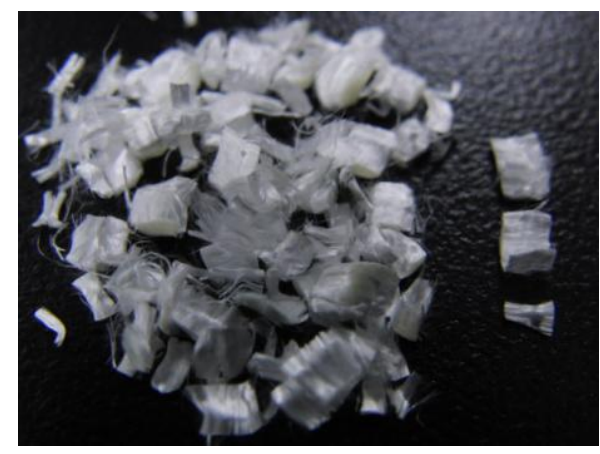

Fig. 1 Acrylic short fiber.

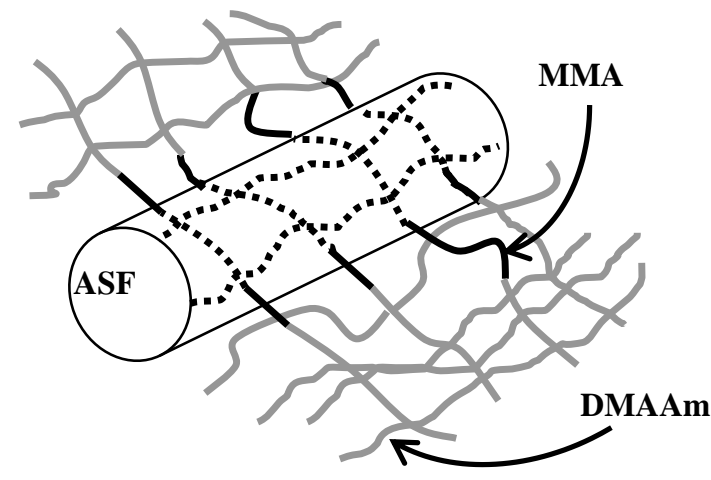

Fig. 2 Schematic of network structure around Acrylic short fiber (ASF).

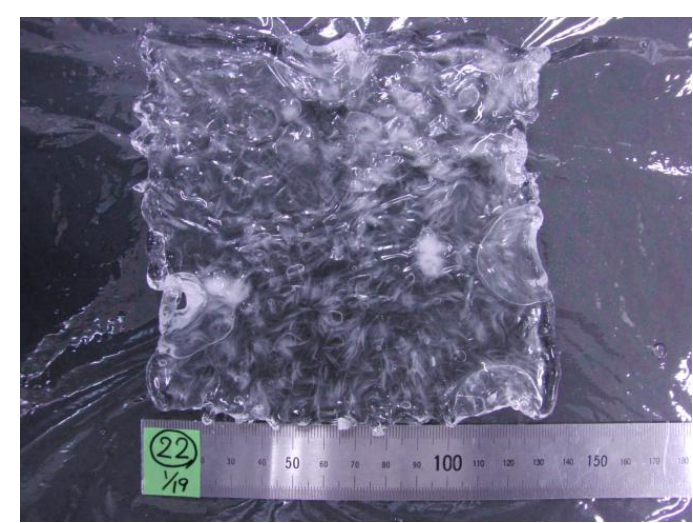

Fig.3 Acrylic short fiber gel (The concentration of MMA is 30mol\%).

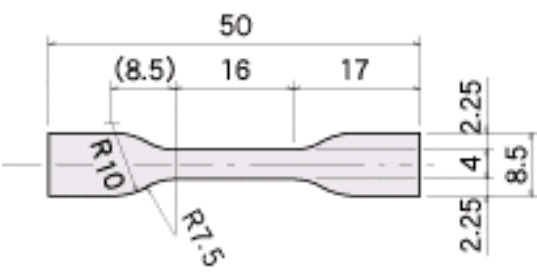

Fig.4 Dumbbell-shaped specimen. 
Table 1 Chemical composition of DMAAm gel

\begin{tabular}{l|c|c|c}
\hline & Monomer & Crosslinker & Photoinitiator \\
& DMAAm[mol/] & MBAA[mol\%] & $\alpha$-keto[mol\%] \\
\hline Standard Sample & 2 & 2 & 0.1 \\
\hline Sample1 & 2 & 0.1 & 0.1 \\
\hline Sample2 & 2 & 0.05 & 0.1 \\
\hline Sample3 & 2 & 0.01 & 0.1 \\
\hline
\end{tabular}

\section{$2 \cdot 3$ 引張試験}

調製した䋊維強化ゲルを平衡㯖潤後，引張試験によって引張破断応力とヤング率を測定した．試験片は引張試験

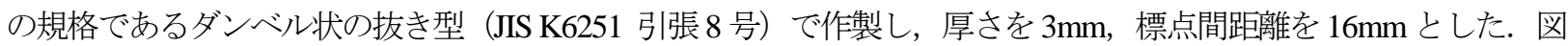
4 にダンベル型試験片を示す. 試験には卓上型材料試験機 STA-1150（オリエンテック）を用い，クロスヘッド速度 $100 \mathrm{~mm} / \mathrm{min}$ で測定した．クロスヘッド速度の意味は，試験器で試験片を挟しでいる部位が，測定中に離れる速度で ある. 引張試験で試験片にかかる応力は, クロスヘッドの速度によっても変わる. 各サンプル 3 回ずつ測定を行な った. 引張試験で観察される材料の歪みは，元の標点間距離の距離に対する標点間距離の変化量から求めた.

\section{3. 実験結果および考察}

引張試験による応力ーひずみ曲線を図 5 に示す. 值は 3 回の測定の平均值から求めた. すべての破断ひずみは 2 ～5 の範囲で，大きなばらつきがみられた．最も破断ひずみが大きいサンプルは図 5 (a) に示した MMA 0mol\%の アクリル短繊維無添加のもので, 最大ひずみ 5 となった. 応力ーひずみ曲線の最大応力から算出したヤング率を図 6 に示した. アクリル短繊維と MMA を同時に添加することにより, ヤング率は増加する傾向があることがわかる.

これは MMA が PDMAAm とアクリル短繊維の架け橋となり結合しているため，ヤング率の大きいアクリル短繊維 と PDMAAm の剥離を妨げヤング率が増加したと考えられる.さらに, MMA30mol\%, アクリル短繊維 $0.3 \mathrm{wt} \%$ 添加 したゲルは, ヤング率がアクリル短䋊維無添加時の約 3 倍となった. 網目のサイズが nm スケールである PDMAAm ゲルに, 高い勒性をもち, 太さが $\mu \mathrm{m}$ スケールのアクリル短䋊維を添加すると, アクリル短繊維はゲルの網目サイ ズより材径が圧倒的に太くゲルとの付着面積が大きな長い補強材（アンカー）として埋め込まれて支持体となり柔 らかいゲルの変形を抑制し強化する（アンカリング効果）ため，ゲルのヤング率を向上させたと考えられる.さら に，PDMAAm とアクリル短繊維の両者に親和性の高い MMA を添加することでアクリル短繊維内部にまで MMA が浸透する．そのため PDMAAm とアクリル短䋊維の接着性が向上し，剛直性繊維のアクリル短繊維が，ゲルのヤ ング率を増加させていると考えられる. 図 7 にはゲルの最大応力の推移を示寸. 值はばらついていたが, MMA を

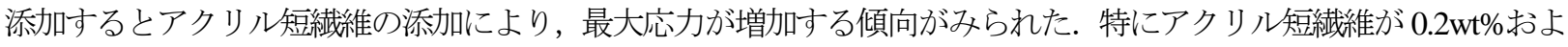
び 0.3wt\%のとき, MMA の添加で最大応力が大きく増加した. 図 5 と比較すると, アクリル短繊維 $0.3 \mathrm{wt} \%$, MMA30wt\%のときには, 最大応力は増加, ヤング率は飛躍的に増加した. しかし, アクリル短䋊維の添加量が $0.4 \mathrm{wt} \%$ や $0.5 \mathrm{wt} \%$ なると，かえって最大応力は減少したため，添加量を増やしすぎると破断しや寸くなる傾向があると考 えた.

そこで, MMA 濃度とアクリル短繊維の含有量の間の関係を考察するために, MMA 濃度を横軸として, 各 MMA 濃度においてヤング率(もしくは最大応力) が最大值となるときのアクリル短繊維の含有量を縦軸とした相関図を, 図 8（もしくは図9）に示寸. 言い換えるとこの図は, 各 MMA 濃度に対する最適なアクリル短纎維の含有量を示し ている.このような最適な対応関係が存在する理由は次のように考えられる. ゲルに添加するアクリル短繊維の濃 度を高めれば，アクリル短䋊維に浸透させることができる MMAの量の上限が増える. アクリル短繊維を MMAに 対して過剩に添加したとき，またはMMA をアクリル短䋊維に対して過剩に添加したとき引張破断応力が減少する と考えられる.つまり, アクリル短繊維に対して MMA が飽和する量が最適值であり, 引張破断応力が増加すると 考えられる. 


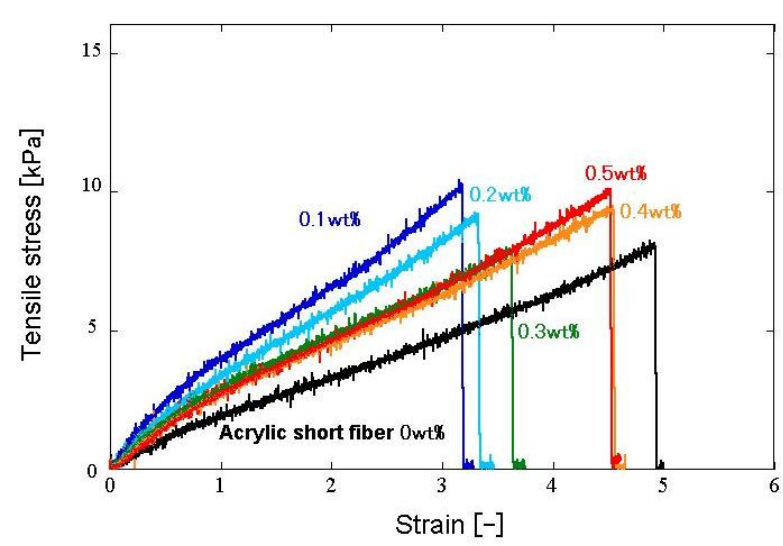

(a) MMA $0 \mathrm{~mol} \%$

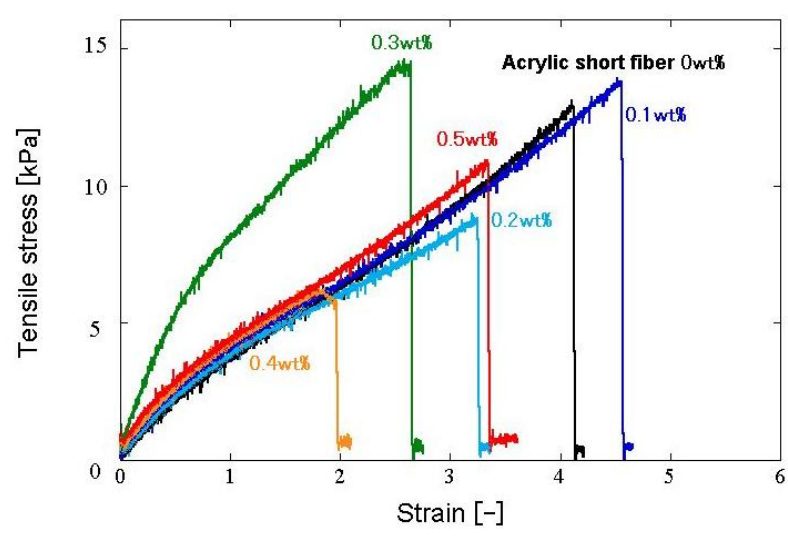

(b) MMA 30mol $\%$

Fig.5 Conventional stress-strain curve of fiber reinforced gels in tensile test.

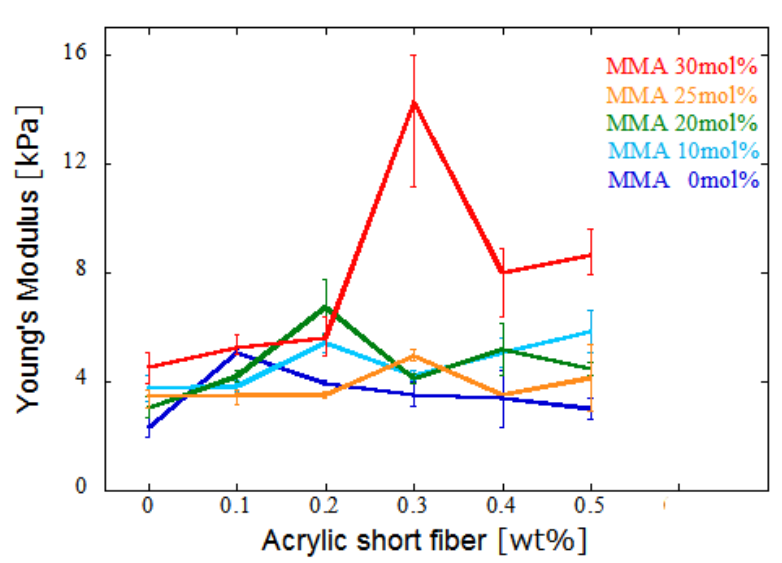

Fig.6 Young's modulus of fiber reinforced gels in tensile test.

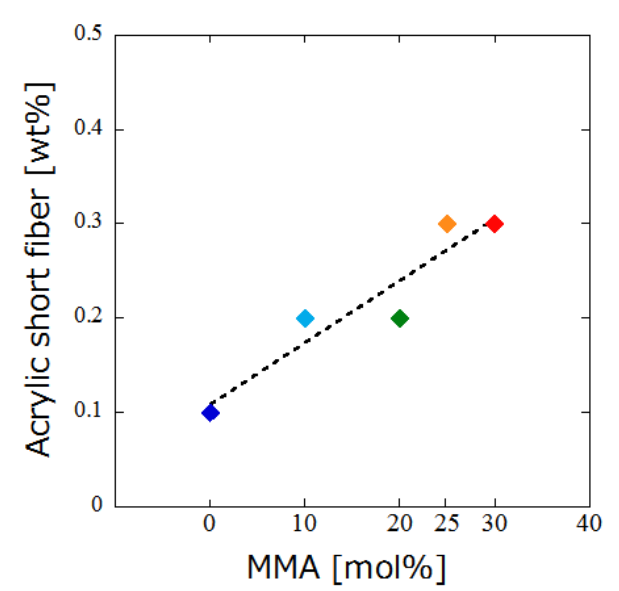

Fig.8 Correlation diagram between the compositions of acrylic short fiber and MMA for the Young's modulus shown in Fig.6. For each concentration of MMA, the optimal conctntration of the fiber exists for the maximum of Young's modulus. The broken line is linearly fitted one to all the data.

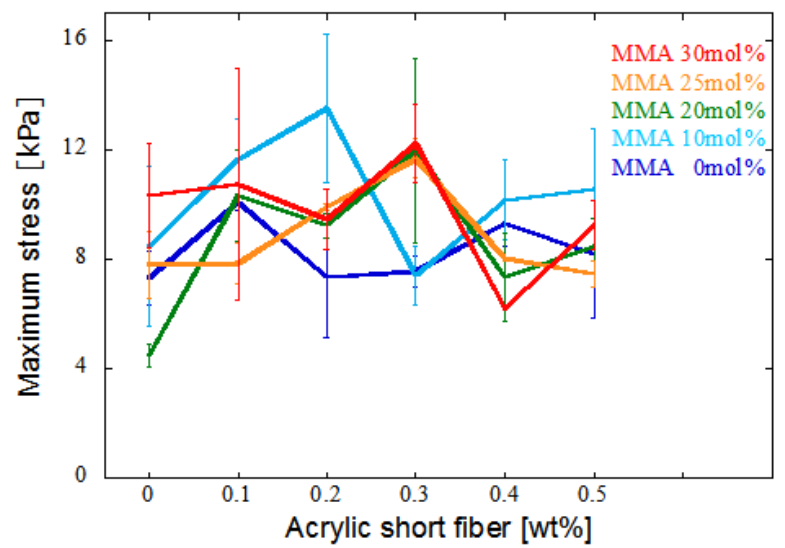

Fig.7 Dependence of maximum stress of fiber reinforced gels on amount of acrylic short fiber and MMA.

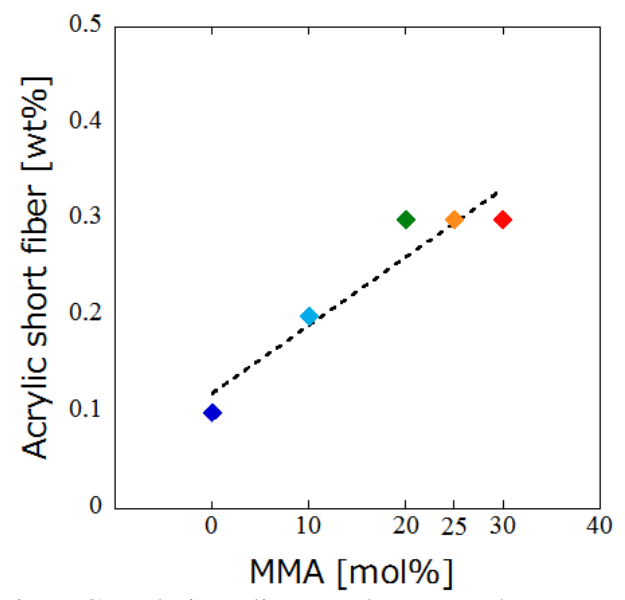

Fig.9 Correlation diagram between the compositions of acrylic short fiber and MMA for the maximum stress shown in Fig.7. For each concentration of MMA, the optimal conctntration of the fiber exists for the maximum of maximum stress. The broken line is linearly fitted one to all the data. 


\section{4. 結言}

アクリル短繊維を加えることで，ゲルのヤング率を最大で $300 \%$ 増加させることに成功した．ゲル内の アクリル短繊維はアンカリング効果によりゲルを強化する。すなわち MMA が PDMAAm とアクリル短繊 維を化学結合で架橋することで接着性が向上し，アクリル短繊維と PDMAAm の剥離が妨げられる。これ により最大破断応力とヤング率が増加したと考察した．アクリル短繊維への MMA の化学結合による浸透 をコントロールし，アクリル短繊維と PDMAAm の接着性の改善をすることで，さらなる最大応力や破断 ひずみの向上が期待される.

\section{文献}

(1) Okumura, Y., and Ito, K., 2001, "The Polyrotaxane Gel: A Topological Gel by Figure-of-Eight Cross-links", Advanced Materials, Vol.13, No.3 (2001), pp. 485-487.

(2) Haraguchi, H., and Takeshita, T., 2002, "Robust bonding and one-step facile synthesis of tough hydrogels with desirable shape by virtue of the double network structure", Advanced Materials, Vol. 14, (2002), pp. 1120-1123.

(3) Gong, J. P., Katsuyama, Y., Kurokawa, T., and Osada, Y., "Double-Network Hydrogels with Extremely High Mechanical Strength”, 2003, Advanced Materials, Vol.15, No.14 (2003), pp. 1155-1158.

(4) Malkoch, M., Vestberg, R., Gupta, N., Mespouille, L., Dubois, P., Mason, A., Hedrick, J., Liao, Q., Frank, C., Kingsbury, K., and Hawker, C., 2006, "Synthesis of well-defined hydrogel networks using click chemistry", Chemical Communications, No.26 (2006), pp. 2774.

(5) Sakai, T., Matsunaga, T., Yamamoto, Y., Ito, C., Yoshida, R., Suzuki, S., Sasaki, N., Shibayama, M., and Chung, U. I., 2008, "Evaluation of Topological Defects in Tetra-PEG Gels", Macromolecules, Vol. 41, (2008), pp. 5379-5384.

(6) Wang, Q., Mynar, J. L., Yoshida, M., Lee, E., Lee, M., Okuro, K., Kinbara, K., and Aida, T., 2010, "High-water-content mouldable hydrogels by mixing clay and a dendritic molecular binder", Nature, Vol. 463, No.7279 (2010), pp. 339-343.

(7) Guvendiren, M., and Shull, K. R., 2007, "Self-assembly of acrylic triblock hydrogels by vapor-phase solvent exchange", Soft Matter, Vol. 3, (2007), pp.619-626.

(8) Yang, W., Furukawa, H., and Gong, J. P., 2008, "Highly Extensible Double-Network Gels with Self-Assembling Anisotropic Structure", Advanced Materials, Vol. 20, No.23 (2008), pp. 4499-4503.

(9) Takada, G., Hidema, R., and Furukawa, H., "Development of Ultrahigh Ductile Gels", Proceedings of the 46th Touhoku Branch Annual Meeting of the Japan Society of Mechanical Engineers, No. 2011-1, (2011), pp.190-191.

(10) Takada, G., Hidema, R., and Furukawa, H., "Ultrahigh Ductile Gels Developed by Inter Cross-linking Network (ICN)”, Journal of Solid Mechanics and Materials Engineering, Vol.6, No.2, (2011), pp.169-177. 